\title{
EPRA International Journal of
} Multidisciplinary Research (IJMR) Peer Reviewed Journal

\section{UNDERGROUND AND ELEVATED METRO RAIL}

\author{
Dr. Awari Mahesh Babu \\ Professor of Civil Engineering, \\ Nalla Narasimha Reddy Education Society's group of Institutions, \\ Hyderabad. T.S. India.
}

DOI: https://doi.org/10.36713/epra3745

\begin{abstract}
The metro rail frameworks are high-limit open vehicles which are by and large observed in urban territories. Checking out the urban vehicle situation in Indian urban communities, this is the full length investigation of the Rapid metro rail framework in India. As of late the metro rail has come up as a favored option of mass vehicle in urban spaces looked with developing populace, high vehicular traffic, and expanded contamination. Metro Route Maps are made according to traffic study and assessed in precise way by utilizing GIS, Global Mapped and discover most brief doable courses. Focusing on the complexities of development setting up, Indian practice with those of its universal counterparts. There are steady advantages to the monetary specialists like government, private transporters, travelers, overall population and untalented workers. This Study focus on significant exercises for future foundation ventures. While the metro rail framework has excitingly improved it's between city networks. This investigation of metro rail clarifies the essentialness and outcome of raised and underground metro rail in India.
\end{abstract}

KEY WORDS: Metro rail, vehicle, travelers, urban, population

\section{INTRODUCTION}

This early on section starts with a survey of the vehicle issues come across by urban areas in the nation. This is trailed by discourses of urbanization in India and the nation's urban vehicle approach, and overall practices in creating metros. Increment in populace has lead to the development of traffic in India. To facilitate the traffic circumstance in the nation and make travel advantageous for the individuals, the administration has presented the metro rail in numerous urban areas. Mass Rapid Transit System in India is normally known as "Metro". It is a conservative method of movement, which aides in decreasing the vitality utilization is eco-accommodating, and it is the explanation for the avoidance of mishaps. The cutting edge structure of metro mentors, the a la mode appearance of metro stations, and unrivaled solace offices are a portion of the reasons why metro is getting to be famous in India. The voyage gives off an impression of being increasingly productive because of the administrations like nourishment outlets, bistros and comfort stores at the metro stations. Fast travel frameworks that work on a selective option to proceed, which is isolated from all methods of transport in a urban region. These frameworks for the most part work with a top speed of $70 \mathrm{~km} / \mathrm{hr}$ and normal speed of 32 to $35 \mathrm{~km} / \mathrm{hr}$ relying upon it is wide measure and system traffic. For a more drawn out movement, you ought to think about normal speed of $32 \mathrm{~km} / \mathrm{hr}$, For Airport express line, normal speed is $54 \mathrm{~km} / \mathrm{hr}$. There has been a developing enthusiasm among policymakers about the significance of rail-based frameworks in India, to address the portability needs of the extending populace in the urban areas. While assessing diverse mass travel alternatives for Indian urban areas, metro frameworks are regularly given inclination because of the conviction that street based frameworks can't oblige limit prerequisites as much as metro frameworks.

India has presented Mass Rapid Transit System (MRTS), which is right now working effectively in 10 urban communities in India. Mass Rapid Transit System has been generally acknowledged as an answer for a large portion of the 
traffic and ecological contamination related issues which significant urban communities all through the world are confronting now. So as to improve the open transportation framework, the Mass Rapid Transit System have been given or being arranged in different pieces of the world. Albeit a large portion of the created nations have just given MRTS in their significant urban communities, the equivalent is deficient in the vast majority of the urban communities in the creating nations, including India. In a perfect world, as the number of inhabitants in a city develops, portion of open transportation should increment for a city. With a populace of 1 or 2 million, the portion of open transportation ought to be around 50 percent- 60 percent. Also the rate portion of open vehicle ought to continuously increment with the populace development of the city, and should reach around 75 percent when the number of inhabitants in the city arrives at the 5 million imprint. Determination of an open transportation framework on a hall in the city, regardless of whether it ought to be street based (High Capacity Bus Systems [HCBS]) or rail-based (for instance, metro rail, mono rail, and so on.) principally relies upon the traffic thickness during the pinnacle hours on that specific passageway. Experience from Indian urban areas have indicated that under blended traffic conditions, containing moderate and quick moving vehicles, street based open transportation framework can ideally convey 8,000 people for every hour per bearing. At the point when traffic thickness crosses that imprint, traffic and ecological contamination related issues or issues increment, under these conditions arrangements of a rail-based mass travel framework that is, a metro rail framework ought to be considered. Metro rail is a type of mass travel open vehicle framework utilizing trains. The metro rail framework, not at all like ordinary rail-based frameworks is evaluation isolated from the other traffic or furnished with discrete option to proceed to maintain a strategic distance from strife with other urban transportation systems. Metro rail development exercises are being embraced in a major manner in India, existing metro rail system of the city of Kolkata and Delhi are being extended, while it is under different phases of development in urban areas like Hyderabad, Jaipur, Kochi and Mumbai. They are electric railroads which work on option to proceed and can't be gotten to by people on foot or some other vehicle. The metro administrations deal with assigned lines and keep running between stations utilizing electrical units on railroad tracks. A few metros likewise run underground administrations, as of now the metro administrations are working in a not very many urban communities, yet the number is probably going to ascend in future with the metro ventures in progress in numerous urban areas. In the majority of the cases, in any event a segment of the rails are set underground (in burrows), while a significant segment stays over the ground (raised). The framework is given in a urban territory and is for the most part worked by power with high limit and recurrence. In the present investigation, basic issues identified with metro rail activities have been talked about in the Indian setting which straightforwardly or in a roundabout way influence its execution, practicality in specialized just a

\section{METHODOLOGY}

There are two sorts of metro rails

- Underground metro rail

- Elevated metro rail

Underground metro rail

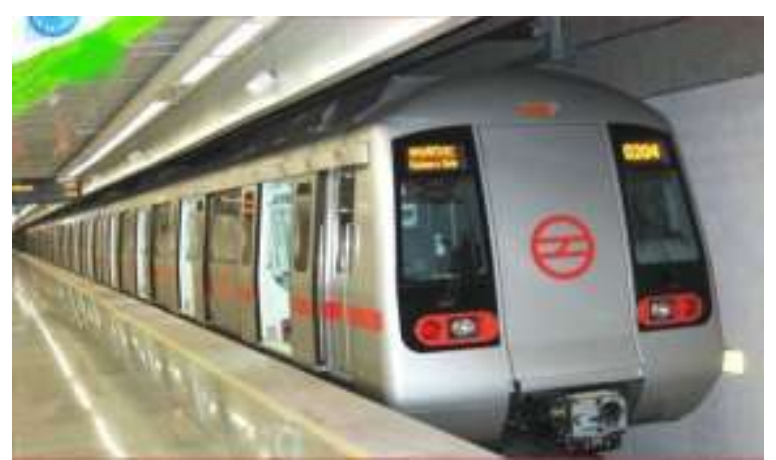

Figure: Underground Metro Rail

Underground burrowing by utilizing TBM (Tunnel Boring Machine) otherwise called a mole, is a machine used to exhume burrows with a roundabout cross segment through an assortment of soil and shake strata. They can drill through hard shake, sand, and nearly anything in the middle. Passage breadths can go from a meter to right around 16 meters. Passages of not exactly a meter or so in distance across are regularly done utilizing trenchless development strategies or flat directional penetrating instead of TBMs. Passage drilling machines are utilized as an option in contrast to penetrating and impacting (D\&B) strategies in shake and traditional hand mining in soil. TBMs have the benefits of restricting the unsettling influence to the encompassing ground and creating a smooth passage divider. This fundamentally diminishes the expense of covering the passage, and makes them reasonable 
to use in vigorously urbanized zones. The significant drawback is the forthright cost. TBMs are costly to develop, and can be hard to move. In any case, as present day passages become longer, the expense of passage drilling machines versus drill and impact is in reality less this is on the grounds that burrowing with TBMs is substantially more proficient and results in a shorter venture.

Urban burrowing has the extraordinary test of necessitating that the ground surface is undisturbed. This implies ground subsidence must be kept away from. The typical technique for doing this in delicate ground is to keep up the dirt weights during and after the passage development. There is some trouble in doing this, especially in fluctuated strata (e.g., drilling through a district where the upper segment of the passage face is wet sand and the lower part is hard shake). TBMs with positive face control, for example, EPB and SS, are utilized in such circumstances. The two sorts (EPB and SS) are fit for diminishing the danger of surface subsidence and voids whenever worked appropriately and if the ground conditions are very much archived. When burrowing in urban situations, different passages, existing utility lines and profound establishments should be tended to in the early arranging stages. The venture must oblige measures to alleviate any unfavorable impacts to other foundation.

\section{Elevated Metro rail}

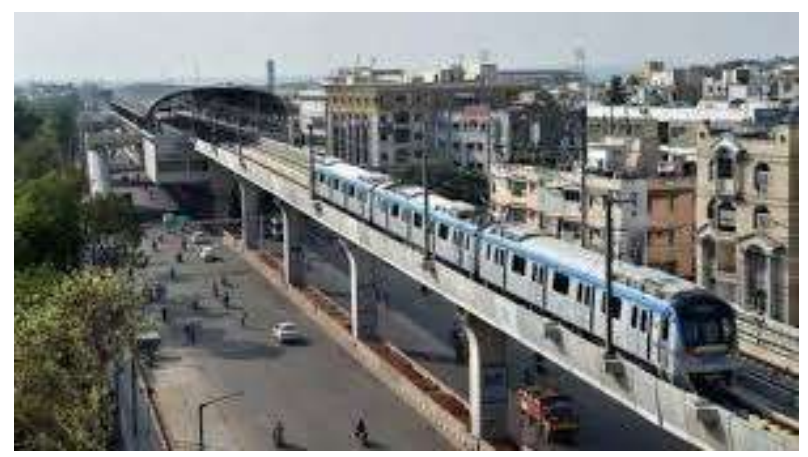

Fig : Elevated Metro rail

The greater part of bridge structures are being developed utilizing pre-thrown sections introduced utilizing the under threw brace procedure. The benefit of this strategy is that it empowers the viaduct deck ranges to be raised quickly on location with least interruption to traffic underneath.

Viaducts are basically multi-spread over scaffolds going across over streets or waterways or valleys. On the Guard train venture, viaducts commonly length in the request for $40 \mathrm{~m}$ to $50 \mathrm{~m}$ between docks. Over the previous months erection of viaduct decks has been continuous at numerous areas along the course. Three supports are being utilized all the while and together they will erect roughly 10.5 kilometers of viaduct deck structure.

\section{COMPARISION}

\section{Similarities}

- $\quad$ State-of-workmanshipplan frameworks

- $\quad$ Automatic entryway shutting offices

- $\quad$ Safety precautionary measure

- $\quad$ Power Back-up Facility

- $\quad$ Fire-safe Coaches

- Emergency Wireless traveler and driver correspondence framework

- $\quad$ Economic cost of Travel

- $\quad$ Average Journey Speed 33Kmph

- Trains will be given at a helpful progress of $3 \mathrm{~min}$.

- $\quad$ Comfortable Standing in $\mathrm{A} / \mathrm{c}$ domain is guaranteed

$\begin{array}{ll}\text { - } & \text { State-of-workmanship } \\ \text { ticketing framework } & \text { electronic } \\ \text { - } & \text { Differences } \\ \text { - } & \text { Construction Cost } \\ \text { - } & \text { Infrastructure Cost } \\ \text { - } & \text { Rehabilitation and Resettlement cost } \\ \text { - } & \text { Litigation Cost } \\ & \text { Cost of Delays because of lawful or } \\ \text { - } & \text { different deterrents } \\ \text { - } & \text { Snvironmental Cost } \\ & \text { Economial Cost Cost }\end{array}$

In short Metro rail is progressed, complex and more secure adaptation of train. There are some essential foundation issues because of which trains can't be updated past certain point that is the reason metro trains came to picture. Here is somekey contrast between it.

1) Coach: Metros having computerized entryways which avoid numerous mishaps. Additionally mentors are increasingly agreeable and outfitted with different propelled frameworks. A/C is likewise an extra preferred position anyway present day mentors of nearby prepares are taking up on this point.

2) Platform: metro stages are completely shut along these lines simple to keep up and perfect and just travelers are permitted on stage so less surge.

3) Ticket: robotized ticket checking and attractive tickets spare time, asset and increment income. 
4) Tracks: completely secured tracks it is possible that it is raised, underground or on the ground however metro tracks are completely secured subsequently its safe and no mishaps on tracks.

5) Electric stock: More sheltered and secured supply track alongside running tracks takes less space additionally not at all like overhead stripped stockpile link in neighborhood trains.

\section{CONCLUSION}

Consequently there ought to be appropriate planning and usage to limit the effect on the condition, so that there will be least bother or no-burden for the individuals. Any framework advancement completed in the city is intended for the individuals living in the city.

- Metro Rail System is required to decrease the traffic on streets.

- This is a genuinely necessary framework to help the present traffic states of the city.

- The social advantages exceed for the underground metro contrasted with the raised metro.

- High immediate and aberrant cost investment funds of underground metro contrasted with raised metro.

Raised Metro is superior to Underground Metro. In the examination region the development of raised metro will have less effect on condition than underground. The focuses watched are as per the following:

The geography of surface level isn't level, and it is hard to burrowed burrow for underground.

\section{REFERENCES}

1. Ramachandran, M. (2012), Metro Rail Projects in India, A study in Project Planning, Oxford

2. University Press, New Delhi.

3. Prof. Dr. S.L. Dhingra, Comparative Evaluation between Elevated and Underground Metro Case Study - Mumbai Metro

4. Anand (2007), "Socio-Economic Impact Assessment Methodology for Urban Transport Projects: Impact of Delhi Metro on Urban Poor", unpublished thesis, IIT Delhi, New Delhi.

5. Rajwardhan Kale, Kartik Kharde, Mohanish Vengurlekar, Shantini Bokil, Collation between Under $g$ round and Elevated Metro System. 